\title{
Estimation of Effect on Gross Domestic Product of Production Factors Using CES and Translog Production Functions: An Application to China Economy
}

\section{Ömer ÖNALAN}

Marmara University - Goztepe Campus: Marmara Universitesi

Hülya BAŞEĞMEZ ( $\sim$ hulyabasegmez@gmail.com )

Beykent University: Beykent Universitesi https://orcid.org/0000-0001-7768-1666

\section{Research}

Keywords: Gross Domestic Product, CES production function, Translog production function, Holt-Winter's method, Ridge regression

Posted Date: December 1st, 2020

DOl: https://doi.org/10.21203/rs.3.rs-114621/v1

License: (c) (1) This work is licensed under a Creative Commons Attribution 4.0 International License. Read Full License 


\title{
Estimation of Effect on Gross Domestic Product of Production Factors Using CES and Translog Production Functions: An Application to China Economy
}

\author{
Ömer Önalan ${ }^{1} \cdot$ Hülya Başeğmez *2
}

\begin{abstract}
In this paper, we investigate the effect on economic growth (GDP) for China's economy with capital, labor and energy input factors by using CES production function and Translog production function. The empirical findings of the study showed that CES, consisting of capital and labor factors, is less efficient than the Translog function consisting of capital, labor and energy input factors for GDP estimation.

The Ridge regression method is used to the parameter estimation of Translog production function using historical data because there is collinearity between variables. Then, based on the fitted Translog production model including capital, labor and energy input factors, the results of the output elasticities for each of the factors and the substitution elasticities between input factors have been dynamically estimated. To predict the future economic growth of the China economy, the inputs of Translog production model are predicted by using Holt-Winter's method. The elasticities of the output of all input factors are positive. According to degrees of the effect on GDP, we can list the factors as labor, capital and energy, respectively. This situation represents the China economy is labor and capital intensive.
\end{abstract}

Keywords: Gross Domestic Product, CES production function, Translog production function, Holt-Winter's method, Ridge regression.

Subject classification codes: C51, C53, E23, 047

${ }^{1}$ ORCID: 0000-0003-3996-3616, Faculty of Business Administration, Marmara University, Istanbul, Turkey, E-mail: omeronalan@marmara.edu.tr

${ }^{2}$ ORCID: 0000-0001-7768-1666, Faculty of Economics and Administrative Sciences, Beykent University, Istanbul, Turkey, E-mail:

hulyabasegmez@gmail.com 


\section{Introduction}

The production process transforms the inputs into outputs. Gross Domestic Product (GDP) in general economy can be described by a production function. Thus, the determination of the functional form of the production function is an important issue in the empirical analysis. There are four different production function models commonly used in the literature. These are the Cobb-Douglas production function for which elasticity of substitution is equal to one, Constant Elasticity of Substitution (CES) production function, Leontief production function and Translog production function. In this study, we used CES production function and Translog production function to establish the impact of capital investments, labor and energy on economic development.

Analyzing the factor substitution is very important to develop the economic policies. In this study, firstly, we used the classic assumption which the elasticities of substitutions are constant and the CES model. But in fact, this assumption may not be realistic. It may change over time. Secondly, we use the Translog function as a model for variable elasticity substitution. In this model, it is avoided using the data of factor prices.

CES production function has a lot of applications in macroeconomics as international trade (Lloyd ve MacLaren, 2002), economic growth (Papageorgiou ve Saam, 2008) and energy economics (McFarland vd., 2004). CES functions are nonlinear and they can also not be linearized. So for reason, conventional linear estimation methods cannot be implemented to them. There are some difficulties in estimating the parameters of CES production function, such as the surface of the objective function having a large flat area and local minimum (Henningsen ve Henningsen, 2012). The popular estimation methods for CES production function are linear Taylor series approximation and non-linear least squares method.

Christensen, Jorgenson, and Lau evaluated the Translog production function as an extension of the Cobb-Douglas production function. (Christensen vd., 1973). 
Then, (Romer, 1986), (Lucas Jr., 1988), (Mankiw, N.G., Romer, D. and Weil, 1992) and (Benhabib ve Spiegel, 1994) have made important contributions. Then, Grey Cobb-Douglas production function is used to estimation of GDP (Onalan ve Basegmez, 2018).

There are many factors that have contributed to GDP, such that capital, labor, energy, optimal allocation of technology sources, innovations, etc. In this study, CES production function and Translog production function models are established to confirm that capital, labor and energy have an important effect on GDP. When fitted to the real data of the production function models, it is generally used multiple regression models. In a multiple regression application, we need to know the future values of the inputs (independent variables) to the prediction of future values of the response variable. Thus, future values of capital, labor and energy input factors are forecasted based on Holt-Winter's method in this study.

The aim of this paper is twofold. Firstly, it is to investigate the output elasticity for each input factor and the elasticity of substitution between capital, labor and energy input factors. Secondly, it is to estimate the future values of GDP which is an indicator of China's Economic growth.

The CES production function and Translog production function are implemented in real data. To predict the future values of GDP, capital, labor and energy input factors are predicted using by Holt-Winter's method, then based on the fitted model is analyzed the variation of the elasticities according to levels of input factors within the considered time period.

The remaining part of this paper is organized as follows. Section II reviews the fundamental properties of CES production function, nested CES function and parameter estimation methods. Section III describes the model framework and the estimation procedures such as Translog production function, Ridge regression method and Holt-Winter's method. In Section IV, we describe the data set, how the data is processed and it is presented the empirical results and discussion. Section V includes the conclusion of the study. 


\section{Constant Elasticity of Substitution (CES) Production Function}

GDP can be considered as a measure of the economic growth of countries. The main factor affecting the GDP is industrial output. The industrial output can be considered as a function of capital and labor inputs (Hossain vd., 2013). In substance, economics production is affected by various environmental factors as capital, labor, agricultural activities, technology, industry, energy, raw materials, etc. Production is a process that converts production factors (inputs) into finished products (outputs).

In the economics literature, the empirical relationship between given the quantity of economics inputs and specified outputs is represented as the production function. One of the main problems for economic governance in the production process is determination of the functional relationship between the production output and input factors. The general form of the production function is described by $f: D \rightarrow R_{+}, D \in R_{+}^{n}$ and $Q=f\left(X_{1}, X_{2}, \ldots, X_{n}\right)$ where $X_{1}, X_{2}, \ldots, X_{n}$ are inputs and $Q$ is production level. This function is a differentiable function of all its inputs. Variables are mostly available capital stock in terms of the value of machinery and buildings and labor in terms of people employed or land in terms of acres. Therefore, it is assumed that the inputs of this function are homogeneous. The production function with $n$ input factors is called $h$ - homogeneous degree, if

$$
f\left(k x_{1}, k x_{2}, \ldots, k x_{n}\right)=k^{h} f\left(x_{1}, x_{2}, \ldots, x_{n}\right), \quad(h>0)
$$

where $k \epsilon R$ and if $h>1$, per percent increase in input levels would result greater than per percent increase in the output level, if $h<1$, per percent increase in input levels would result in less than per percent increase in output and $h=1$ represent the constant return to scale.

The production functions are characterized according to technology elasticity of substitution and return to scale.

Hicks elasticity of substitution measure to a production function with more than two inputs is described as (Stern, 2011),

$$
\sigma_{i j}=-\frac{\partial \ln \left(X_{i} / X_{j}\right)}{\partial \ln \left(\left(\partial Q / \partial X_{i}\right) /\left(\partial Q / \partial X_{j}\right)\right)}
$$




\subsection{Functional form of CES production function}

The Constant - Elasticity of Substitution (CES) production function originally is given by (Arrow vd., 1961). It is a generalization of the Cobb-Douglas production function. The CES function puts a restriction on elasticity substitution of being constant along the whole isoquant. The CES production function assumes that the elasticities of substitution between any two inputs are the same.

The CES production function has many forms. In this study, we will use the CES production function which is proposed by Kmenta with capital and labor inputs (Kmenta, 1967). It is given as follows,

$$
Q=A\left[\delta K^{-\rho}+(1-\delta) L^{-\rho}\right]^{-\vartheta / \rho}
$$

where $Q$ denotes the total value of output, $L$ denotes input of labor which is measured in men-per (and hour) year, $K$ represents the capital input which is measured in money term, $A \in[0, \infty)$ represents the productivity (technologic progress level), $\delta \in[0,1]$ denotes the inputs' optimal distribution, $\rho \in[-1,0) \cup$ $(0, \infty)$ represents the elasticity of substitution and $\vartheta \in(0, \infty)(\vartheta=K / L>0)$ is the function's homogenous order or rate of return to scale (degree of homogeneity). In the original form of CES, parameter $\vartheta$ was taken as $\vartheta=1$. If $\vartheta=1$, constant return to scale, if $\vartheta<1$, decreasing return to scale and if $\vartheta>1$, increasing return to scale.

The elasticity of substitution (EOS) of CES function is written as,

$$
\sigma=\frac{\partial \ln (K / L)}{\partial \ln \left(M P_{L} / M P_{K}\right)}=\frac{1}{1+\rho} \geq 0 .
$$

The logarithmic form of CES function is given by

$$
\ln Q=\ln \gamma-\frac{\vartheta}{\rho} \ln \left[\delta K^{-\rho}+(1-\delta) L^{-\rho}\right] .
$$

Uzawa (1962) and McFadden (1963) tried to extent the CES function to $n$-input factor production functions. Marginal productivity of labor for CES function is given by

$$
\frac{\partial Q}{\partial L}=(1-\delta) A^{-\rho}\left(\frac{Q}{L}\right)^{\rho+1}
$$

Then,

$$
\frac{Q_{L}}{Q}=(1-\delta) A^{-\rho}\left(\frac{Q}{L}\right)^{\rho+1}
$$


In Eq. (4), taking the logarithm of both side, we obtained

$$
\ln \left(Q_{L} / Q\right)=\ln \left((1-\delta) A^{-\rho}\right)+(\rho+1) \ln (Q / L) .
$$

Eq. (5) represents the relationship between nominal wage, the market price of production and average production.

\subsection{Parameter estimation of CES production function}

CES production function is nonlinear in parameters, so it cannot be linearized to estimate the parameters using the traditional linear estimation methods. In the parameter estimation of CES production function is used to non-linear fitting techniques. In the estimation process, we assume that input variables are nonstochastic or if they are stochastic, independent of disturbance term (Hoff, 2002).

In general, two approaches widely used in CES parameter estimation are linear Taylor series approach and non-linear least squares method. We can use a linear approach with respect to $\rho$.

\subsection{Estimating the CES function using Kmenta Approximation}

$\ln Q$ series expanding the Taylor series around the $\rho=0$ and discarding the terms of third and higher order expanding leads the following form (Kmenta, 1967),

$$
\ln Q_{i}=\ln \gamma+\vartheta \delta \ln K_{i}+\vartheta(1-\delta) \ln L_{i}-\left(\frac{1}{2}\right) \rho \vartheta \delta(1-\delta)\left[\ln K_{i}-\ln L_{i}\right]^{2}+\varepsilon_{i}
$$

Let we define the new variables as,

$$
\begin{gathered}
Y^{*}=\ln Q_{i}, \quad X_{1}^{*}=\ln K_{i}, \quad X_{2}^{*}=\ln L_{i}, \quad X_{3}^{*}=\left[\ln K_{i}-\ln L_{i}\right]^{2}, \\
\beta_{0}=\ln \gamma, \quad \beta_{1}=\vartheta \delta \quad, \quad \beta_{2}=\vartheta(1-\delta) \quad, \quad \beta_{3}=-\left(\frac{1}{2}\right) \rho \vartheta \delta(1-\delta) .
\end{gathered}
$$

Then, Eq. (6) can be written as follows according to this new parameterization.

$$
Y^{*}=\beta_{0}+\beta_{1} X_{1}^{*}+\beta_{2} X_{2}^{*}+\beta_{3} X_{3}^{*}+\varepsilon
$$

The application of the ordinary least squares method yields the following parameter estimations (Mahaboob vd., 2017),

$$
\hat{\gamma}=e^{\widehat{\beta}_{0}}, \quad \hat{\delta}=\frac{\widehat{\beta}_{1}}{\widehat{\beta}_{1}+\widehat{\beta}_{2}}, \quad \hat{\vartheta}=\hat{\beta}_{1}+\hat{\beta}_{2}, \quad \hat{\rho}=-2\left(\frac{\widehat{\beta}_{1}+\widehat{\beta}_{2}}{\widehat{\beta}_{1} \widehat{\beta}_{2}}\right) \hat{\beta}_{3} .
$$

The disadvantage of this approach is that it gives reliable results if $\rho$ is close the point zero (Thursby ve Lovell, 1978). 
The substitution elasticity of (EOS) $\sigma$ is a function of $\rho$ and estimated as,

$$
\hat{\sigma}=\frac{1}{1+\hat{\rho}} .
$$

\subsection{Nested CES Production Function}

A nested production function is given by (Henningsen vd., 2019), (Kemfert, 1998),

$$
Q_{t}=e^{m t} A\left[a\left(b K_{t}^{-\alpha}+(1-b) E_{t}^{-\alpha}\right)^{\beta / \alpha}+(1-a) L_{t}^{-\beta}\right]^{-\gamma / \beta}
$$

where $a$ and $b$ denote the share parameters denoting input factor contributions to output. $\alpha$ and $\beta$ denote the substitution parameters, $A \geq 0$ represents the productivity (efficient), $m$ denotes the annual rate of technological change, $t$ is the time in years and Q denotes the output. In the single level CES function, all input factors have the same substitution elasticity with each other. However, the nested CES function allows the different substitution elasticities between the factors.

When the model is applied the real data, firstly capital and energy combined into an intermediate input using a two-input CES function with share parameter $b$ and substitution parameter $\alpha$. Secondly, this intermediate input is combined with labor $L$ into output $Q$ using another CES function with share parameter $a$ and substitution parameter $\beta$.

$$
\begin{gathered}
Q_{t}=A e^{m t} X^{-\gamma / \beta} \\
X=a Y^{\beta / \alpha}+(1-a) L^{-\beta} \\
Y=b K^{-\alpha}+(1-b) E^{-\alpha} \\
\rho_{\text {in }}=\frac{1}{1+\alpha} \quad \text { and } \quad \rho_{\text {out }}=\frac{1}{1+\beta}
\end{gathered}
$$

$\rho_{\text {in }}$ and $\rho_{\text {out }}$ are inner and outer nested substitution parameters, respectively.

The parameters of nested CES function is estimated using non-linear least squares method as,

$$
\min _{A, m, a, b, \alpha, \beta} \sum_{t}\left(\ln Q_{t}-m t-\ln A+\frac{1}{\beta} \ln \left[a\left(b K_{t}^{-\alpha}+(1-b) E_{t}^{-\alpha}\right)^{\beta / \alpha}+(1-a) L_{t}^{-\beta}\right]\right)^{2} .
$$


To estimate the parameters of CES function, Kemfert (1998) is used the statistical software SHAZAM.

\section{Translog Production Function}

The Translog function belongs to the quadratic response surface methodology. The transcendental logarithmic function (Translog production function) was first introduced by (Christensen vd., 1973). The Translog production function is a more general form of variable elasticity of substitution. It does not impose any restrictions on the substitutability between different input factors. A Translog production function can be view as a second-order Taylor approximation for arbitrary function (Lin ve Liu, 2017). The Translog function is widely used to detect the substitution effect of explanatory variables. The interactions between the components of interested system may be described as a quadratic response surface as follows,

$$
\begin{gathered}
\hat{y}=a_{0}+a_{1} x_{1}+a_{2} x_{2}+a_{3} x_{3}+a_{12} x_{1} x_{2}+a_{12} x_{1} x_{2}+a_{13} x_{1} x_{3}+a_{23} x_{2} x_{3} \\
+a_{11} x_{1}^{2}+a_{22} x_{2}^{2}+a_{33} x_{3}^{2}
\end{gathered}
$$

Generally, a Translog production function is described as follows;

$$
\ln Q_{t}=\beta_{0}+\sum_{i} \beta_{i} \ln X_{i}+\sum_{i} \beta_{i i}\left(\ln X_{i}\right)^{2}+\frac{1}{2} \sum_{i \neq j} \beta_{i j}\left(\ln X_{i}\right)\left(\ln X_{j}\right)+\varepsilon
$$

Using the symmetry property of partial derivatives, i.e. $\frac{1}{2}\left(\beta_{i j}+\beta_{j i}\right)=\beta_{i j}$, we will use the following form of the Translog production function in practice,

$$
\ln Q_{t}=\beta_{0}+\sum_{i=1}^{n} \beta_{i} \ln X_{i}+\sum_{i=1}^{n} \beta_{i i}\left(\ln X_{i}\right)^{2}+\sum_{j>1}^{n} \beta_{i j}\left(\ln X_{i}\right)\left(\ln X_{j}\right)+\varepsilon
$$

where $Q$ is the output, $X_{i}$ are inputs and $\beta_{0}, \beta_{i}$ and $\beta_{i j}$ are parameters to be estimated. Parameter $\beta_{0}$ denotes the technology level.

Generally, response surface function with $n$ - variables is estimated as follows. Polynomial coefficients are determined based on least squares regression method. We assume that there are $k$ observation points.

$$
\boldsymbol{Q}=\left[\begin{array}{c}
\ln Q_{1} \\
\ln Q_{2} \\
\vdots \\
\ln Q_{\mathrm{k}}
\end{array}\right]
$$




$$
\begin{gathered}
\boldsymbol{X}=\left[\begin{array}{cccccccccc}
1 & \ln X_{11} & \cdots & \ln X_{1 n} & \left(\ln X_{11}\right)^{2} & \cdots & \left(\ln X_{1 n}\right)^{2} & \ln X_{11} \ln X_{12} & \cdots & \ln X_{1 n} \ln X_{1 n-1} \\
1 & \ln X_{21} & \cdots & \ln X_{2 n} & \left(\ln X_{21}\right)^{2} & \cdots & \left(\ln X_{2 n}\right)^{2} & \ln X_{21} \ln X_{22} & \cdots & \ln X_{2 n} \ln X_{2 n-1} \\
\vdots & \vdots & \vdots & \vdots & \vdots & \vdots & \vdots & \vdots & \vdots & \vdots \\
1 & \ln X_{k 1} & \cdots & \ln X_{k n} & \left(\ln X_{k 1}\right)^{2} & \cdots & \left(\ln X_{k n}\right)^{2} & \ln X_{k 1} \ln X_{k 2} & \cdots & \ln X_{k n} \ln X_{k n-1}
\end{array}\right] \\
\\
\boldsymbol{\beta}=\left[\begin{array}{cccccccccc}
\beta_{0} & \beta_{1} & \cdots & \beta_{n} & \beta_{11} & \cdots & \beta_{n n} & \beta_{12} & \cdots & \beta_{n, n-1}
\end{array}\right]^{T} \\
\boldsymbol{\varepsilon}=\left[\begin{array}{ccccc}
\varepsilon_{2} & \varepsilon_{2} & \cdots & \varepsilon_{2}
\end{array}\right]^{T} \\
\boldsymbol{Q}=\boldsymbol{X} \boldsymbol{\beta}+\boldsymbol{\varepsilon} \\
\hat{\beta}=\left(\boldsymbol{X}^{T} \boldsymbol{X}\right)^{-1} \boldsymbol{X}^{T} \boldsymbol{Q}
\end{gathered}
$$

The elasticity of output with respect to input $X_{i}$ is given as,

$$
f_{i}=\frac{\partial Q}{\partial X_{i}} \frac{X_{i}}{Q}=\beta_{i}+\sum_{j=1}^{n} \beta_{i j} \ln X_{j}
$$

The marginal product of input $X_{i}$ is given as,

$$
y_{i}=\frac{\partial Q}{\partial X_{i}}=\left[\beta_{i}+\sum_{j=1}^{n} \beta_{i j} \ln X_{j}\right] \cdot \frac{Q}{X_{i}}
$$

A Translog production function with $(n=3)$ three input factors $Q=$ $f(K, L, E)$ which includes the capital stock, labor force and energy consumption is defined as;

$$
\begin{aligned}
\ln \left(Q_{t}\right)=\beta_{0}+ & \beta_{K} \ln K_{t}+\beta_{L} \ln L_{t}+\beta_{E} \ln E_{t}+\beta_{K K}\left(\ln K_{t}\right)^{2} \\
& +\beta_{L L}\left(\ln L_{t}\right)^{2}+\beta_{E E}\left(\ln E_{t}\right)^{2}+\beta_{K L}\left(\ln K_{t} \ln L_{t}\right) \\
& +\beta_{K E}\left(\ln K_{t} \ln E_{t}\right)+\beta_{L E}\left(\ln L_{t} \ln E_{t}\right)
\end{aligned}
$$

In order for a production function to have consistent and desired properties the following three conditions are required, $i$ ) monotonically increasing, $i i$ ) continuity, iii) exact concave. A Translog function generally satisfies these conditions. The exact concavity property of Translog function is tested using the Hessian matrix.

The output elasticity respect to input factors,

- The output elasticity of Capital,

$$
f_{K}=\frac{d Q / Q}{d K / K}=\beta_{K}+\beta_{K L} \ln L_{t}+\beta_{K E} \ln E_{t}+2 \beta_{K K} \ln K_{t}
$$


- The output elasticity of Labor force,

$$
f_{L}=\frac{d Q / Q}{d L / L}=\beta_{L}+\beta_{L K} \ln K_{t}+\beta_{L E} \ln E_{t}+2 \beta_{L L} \ln L_{t}
$$

- The output elasticity of Energy,

$$
f_{E}=\frac{d Q / Q}{d E / E}=\beta_{E}+\beta_{K E} \ln K_{t}+\beta_{L E} \ln L_{t}+2 \beta_{E E} \ln E_{t}
$$

The elasticity of substitution is described by the ratio between the percentage changes in the proportion of input factors. Substitution elasticity indicates how hard to substitute one input factor with the other. It is varying zero to infinity. The substitution elasticity between different factors is given as (Lin ve Ahmad, 2016), (Lin ve Liu, 2017),

- The substitution elasticity between Capital and Labor,

$$
\sigma_{K L}=\left[1+\left[-\beta_{K L}+\left(\frac{f_{K}}{f_{L}}\right) \beta_{L L}\right]\left(-f_{K}+f_{L}\right)^{-1}\right]^{-1}
$$

- The substitution elasticity between Capital and Energy,

$$
\sigma_{K E}=\left[1+\left[-\beta_{K E}+\left(\frac{f_{K}}{f_{E}}\right) \beta_{E E}\right]\left(-f_{K}+f_{E}\right)^{-1}\right]^{-1}
$$

- The substitution elasticity between Labor and Energy,

$$
\sigma_{L E}=\left[1+\left[-\beta_{L E}+\left(\frac{f_{L}}{f_{E}}\right) \beta_{E E}\right]\left(-f_{L}+f_{E}\right)^{-1}\right]^{-1}
$$

\subsection{Estimation of Translog Production Function}

The Translog function can be considered as a second-order Taylor approximation of an arbitrary function. It is also similar to a linear regression model according to coefficients. Thus, the parameters of Translog production function in Eq.(13) can be estimated using the Ordinary Least Square method (OLS). 


\subsection{Ridge Regression}

The linear regression model is given by,

$$
Y=\beta X+e
$$

where $Y$ is a vector of the dependent variable, $X$ describes $n \times p$ explanatory variables. $e$ is random error. The assumptions of regression model are that $E(e)=$ $0, \operatorname{Var}(e)=\sigma^{2} I_{n}, e$ is a random variable that has a normal distribution. There is not a relationship between independent variables and residuals.

The collinearity phenomena occur when there is linear or approximately linear relationship between two or more independent variables. In the existence of collinearity in the regression model, The OLS method is to be biased and singular. To obtain sensitive parameter estimation, the collinearity must be eliminated. In this study, the independent variables without removing from the model, to eliminate the collinearity, we will use the ridge regression estimator. We may detect the existing collinearity using one of the following methods:

(1) Correlation coefficient: If the correlation coefficient $r>0,75$, we suspect from the collinearity

(2) Variance Inflation Factor (VIF): VIF value is calculated as,

$$
C_{i j}=\frac{1}{1-R_{i j}}
$$

where, $R_{i j}$ is partial correlation. If $C_{i j}>10$, there is collinearity.

Ridge regression is a biased regression estimation method. Ridge regression estimator has proposed by (Hoerl ve Kennard, 1970). Ridge regression method is used to eliminate the collinearity problem in data analysis. Ridge regression is an improvement version of OLS method.

In the presence of multicollinearity, a constant small value of $k$ is added to the diagonal elements in correlation matrix $\left(X^{\prime} X\right)$ to reduce the dependence on independent variables. Ridge estimator is given by,

$$
\hat{\beta}(k)=\left(X^{\prime} X+k I\right)^{-1} X^{\prime} Y
$$


where $k(0<k<1)$ is ridge parameter (shrinkage parameter) and $I$ is the identity matrix. When $k=0$ the ridge estimator $\hat{\beta}$ is the OLS estimation (Hrishikesh D. Vinod, 1978). Covariance matrix for ridge estimator is,

$$
\operatorname{Var}(\hat{\beta})=\sigma^{2}\left(X^{\prime} X+k I\right)^{-1} X^{\prime} X\left(X^{\prime} X+k I\right)^{-1}
$$

where $\hat{\sigma}^{2}=\frac{1}{n-p} \sum_{i=1}^{n} e_{i}^{2}$ and $e_{i}=y_{i}-\hat{y}_{i}$. Total MSE of the ridge estimator is given by (Hoerl ve Kennard, 1970).

$$
\operatorname{MSE}(\hat{\beta})=\sigma^{2} \sum_{i=1}^{p} \lambda_{i}\left(\lambda_{i}+k\right)^{-1}+k^{2} \beta^{\prime}\left(X^{\prime} X+k I\right)^{-2} \beta
$$

where $\lambda_{i}$ are the eigenvalue of $\left(X^{\prime} X\right)$ correlation matrix. The choice of appropriate $k$ value (a) the regression coefficients must be stable, (b) Variance Inflation Factor (VIF) must be small. In the literature, there are different methods to obtain optimal value of ridge parameter $k$. The most popular of them is that the $\hat{\beta}(k)$ values are plotted with respect to the values of $k$, then the value of $\hat{\beta}(k)$ that is stable is selected as the optimal ridge parameter $k$.

Let the Eigenvalues of $\left(X^{\prime} X\right)$ correlation matrix $\lambda_{\max }=\lambda_{1}>\lambda_{2}>\cdots>$ $\lambda_{p}=\lambda_{\min }$, then

$$
k \leq \frac{\lambda_{\max }-100 \lambda_{\min }}{99}
$$

To estimate the value of $k$ is given by (Muniz ve Kibria, 2009),

$$
k=\left(\prod_{i=1}^{p} \frac{1}{m_{i}}\right)^{1 / p} \quad, \quad m_{i}=\left(\frac{\widehat{\sigma}^{2}}{\widehat{\widehat{\beta}}_{i}^{2}}\right)^{1 / 2}
$$

VIF show how the variance of an estimator is inflated by the presence of multicollinearity. When the variance of an estimator $R_{i j}$ approaches 1 , collinearity increases. Any value of VIF that is greater than 10 strongly indicates the presence of collinearity.

\subsection{Holt-Winter's Method}

We will use the Holt-Winter's exponential smoothing method to get the basic forecast values of the Capital, Labor and Energy input variables. This method is a common seasonal forecasting method. The multiplicative Holt-Winter's method is 
described following three basic equations (Dhakre vd., 2016), (Hamilton J. D., 1994) and (Prado ve West, 2010),

Exponential trend for long-term trend: $\quad S_{t}=\alpha\left(\frac{y_{t}}{I_{t-p}}\right)+(1-\alpha)\left(S_{t-1}+b_{t-1}\right)$

Trend smoothing $\quad: \quad b_{t}=\beta\left(S_{t}-S_{t-1}\right)+(1-\beta) b_{t-1}$

Seasonal smoothing

$$
: \quad I_{t}=\gamma\left(\frac{y_{t}}{S_{t}}\right)+(1-\gamma) I_{t-p}
$$

Forecasting

$$
: \quad F_{t+m}=\left(S_{t}+b_{t}\right) I_{t+m-p}
$$

where $\alpha, \beta$ and $\gamma$ are parameters takes the values in interval $[0,1], t$ is the time period, $y_{t}$ is observed value of series at time $t$.

\section{Empirical Analysis}

In this study, we use the annual GDP series as a proxy of aggregate national economic level for China economy. We estimated the future economic growth pattern of China by focusing on the 1994-2014 period. We use the annual data gross domestic product Q ( 0.1 billion yuan) as an output, fixed asset investment $\mathrm{K}(0.1$ billion yuan), the number of employees L (10,000 people) and total energy consumption E (10,000 tons of standard coal) as input factors to analyze the China economy between 1994-2014. Data are obtained from World Bank's World development indicators (WDI) China Statistical Yearbook and China Energy Yearbook (CSYD) as published by China's National Bureau of Statistic and by (Cheng ve Han, 2017).

It was estimated the future values of GDP which is a function of capital, labor and energy input factors by using Improved GM(1,1) Model and Grey CES production function. Firstly, we investigated the effect on the economic growth of capital and labor by using CES production function. The model parameters are estimated using Kmenta approach and we predicted the economic growth.

Capital $\left(K_{t}\right)$ : No capital stock data is reported in the China statistical system. The time series of capital is usually not found in economics databases. It is obtained from other sources. It is calculated using perpetual inventory method (Raymond W. Goldsmith, 1951). 


$$
K_{t}=I_{t}+\left(1-\delta_{t}\right) K_{t-1}
$$

where $K_{t}$ is capital stock in year $t, I_{t}$ is investment in year $t$. Initial capital stock $K_{0}$ is determined as follows,

$$
K_{0}=\frac{I_{0}}{\overline{G D P}+0,05}
$$

Labor $(L)$ : The number of employees. Data obtained from China Statistical Yearbook.

Energy consumption $\left(E_{t}\right)$ : The data on energy consumption taken from China Statistical Yearbook and APEC energy database.

\subsection{Parameter Estimation of CES Production Function}

The fit of the estimates of CES production function is given in Table1.

Table 1. The regression estimation results

\begin{tabular}{lllcl}
\hline & Coefficients & Standard Error & t-Stat & P-value \\
\hline Intercept & -35.987 & 13.039 & -2.760 & 0.013 \\
$\ln K$ & 0.575 & 0.051 & 11.228 & 0.000 \\
$\ln L$ & 3.708 & 1.213 & 3.058 & 0.007 \\
$\left(\ln \left(\frac{K}{L}\right)\right)^{2}$ & 0.019 & 0.021 & 0.939 & 0.361
\end{tabular}

Adjusted R Square $=0.997, \quad$ F statistics $=2213.223$

Table 2. Parameter values of CES production function

\begin{tabular}{ccccccc}
\hline$\delta$ & $1-\delta$ & $\theta$ & $\rho$ & $\sigma$ & $\gamma$ & $-\theta / \rho$ \\
\hline 0.134 & 0.866 & 4.283 & -0.078 & 1.085 & $e^{-35.987}$ & 54.72 \\
\hline
\end{tabular}

Using the estimated parameter values, CES function can be rewritten as,

$$
\hat{Q}_{C E S}=e^{-35.987}\left[0.134 K^{0.078}+0.866 L^{0.078}\right]^{54.72} .
$$

The actual and fitted values graphic is presented in Fig.1. 
Figure 1. Actual GDP and Estimated GDP obtained from Kmenta Approach

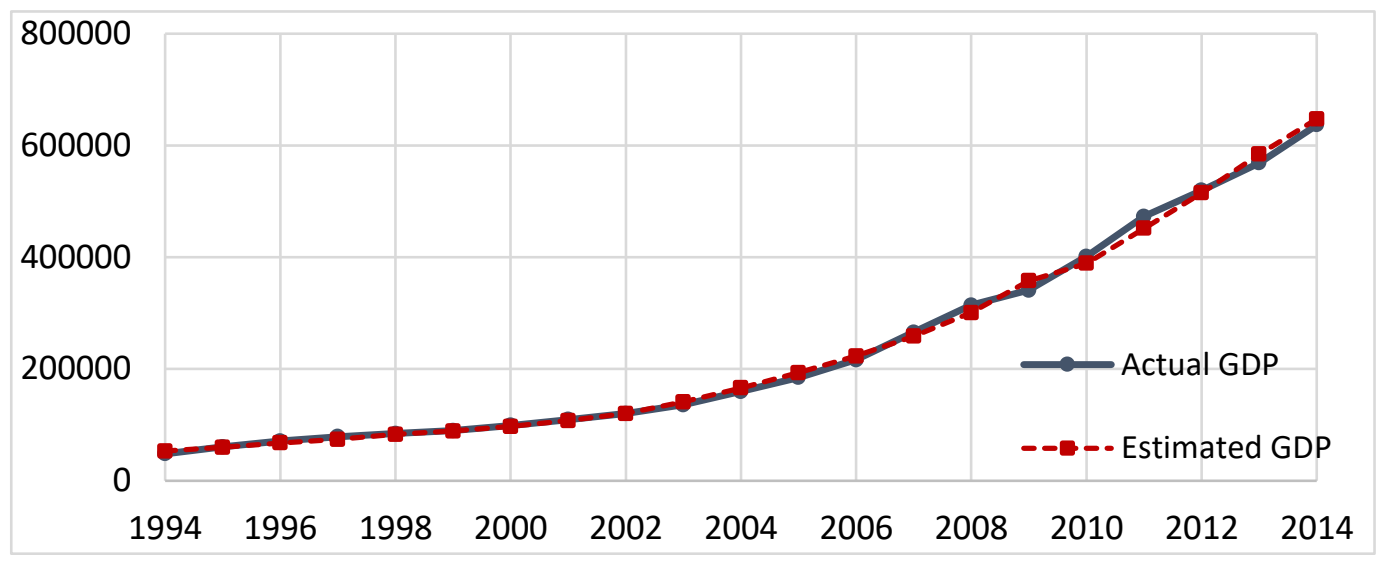

The estimated value of elasticity of substitution $\hat{\sigma}_{C E S}=1.085$ denotes that CES production function may be a suitable model to describe the China economic growth, according to $\hat{\sigma}_{C E S}$ estimation we can say that the general economy has a substitution potential between capital and labor inputs.

Substituting the input factor that has high unit price with the input factors that have relatively lower input price, the total production costs can be reduced.

The values of $\hat{\delta}=0.134$ and $1-\hat{\delta}=0.866$ imply the distribution rate (share) of total output $(Q)$ via capital (values of building, lands, machinery, other tools etc.) and labor (wages and salaries), respectively.

Parameter $\widehat{\vartheta}=4.283$ represents the elasticity of scale, this result implies that China economy has increasing return to scale.

\subsection{Translog production model}

In this section, we want to build a Translog production function with the capital, labor and energy input factors. Due to interaction and squared terms of the input factors in Eq. (13). The model is likely to suffer from severe multicollinearity. So before establishing a regression equation for Translog production function, we must detection the multicollinearity existing.

The condition number is above 30 , the regression has significant multicollinearity. VIF is an important indicator to measure the severity of multicollinearity. If $V I F>10$, then there is multicollinearity. In this case, Ridge regression is feasible method to deal with multicollinearity. In the parameter estimation process is used the software of NCSS 2007 and regression results are given in Table 4. 
Table 3. Multicollinearity Test

\begin{tabular}{llclll}
\hline Variable & $\begin{array}{l}\text { Detection } \\
\text { tolerance }\end{array}$ & $R^{2}$ & VIF & $\begin{array}{l}\text { Multicollinearity } \\
\text { problem is present? }\end{array}$ & $\begin{array}{l}\text { Condition } \\
\text { Number }\end{array}$ \\
\hline GDP & $0.3 \%$ & $99.7 \%$ & 328.90 & True & \\
K & $0.7 \%$ & $99.3 \%$ & 152.89 & True & 27112687.43 \\
L & $13.4 \%$ & $86.6 \%$ & 7.45 & True & \\
E & $1.8 \%$ & $98.2 \%$ & 55.64 & True & \\
\hline
\end{tabular}

Table 4 shows the estimation results of the Ridge regression with the Ridge parameter $k=0.0006$.

Table 4. Ridge Regression Coefficient for $k=0.006$

\begin{tabular}{llllll} 
& Variables & Coefficient & Std. Error & $\begin{array}{l}\text { Standardized } \\
\text { Coefficient }\end{array}$ & VIF \\
R-Squared: 0.9962 & $\beta_{0}$ & -22.337470 & & & \\
Sigma 0.0669 & $\ln K$ & 0.145865 & 0.027855 & 0.204000 & 4.372500 \\
& $\ln L$ & 1.748346 & 0.474985 & 0.091300 & 1.771700 \\
& $\ln E$ & -0.013067 & 0.089362 & -0.007000 & 6.517000 \\
& $\ln K \ln K$ & 0.007516 & 0.001731 & 0.240500 & 8.840200 \\
& $\ln L \ln L$ & 0.076086 & 0.021126 & 0.088900 & 1.755400 \\
& $\ln E \ln E$ & 0.001052 & 0.003231 & 0.013800 & 5.151300 \\
& $\ln K \ln L$ & 0.012340 & 0.002304 & 0.200100 & 4.022500 \\
& $\ln K \ln E$ & 0.007475 & 0.001070 & 0.173800 & 1.784400 \\
& $\ln L \ln E$ & 0.000447 & 0.006575 & 0.002900 & 5.340500 \\
\hline
\end{tabular}

According to the result of Ridge regression, the fitting degree value of Translog equation is $99.62 \%$ and the multicollinearity of variables is effectively eliminated. The coefficients of technological progress input and energy input are negative and other variables have positive coefficients.

According to Table 4, the corresponding Ridge regression equation can be written as follows,

$$
\begin{aligned}
& \ln \hat{Q}_{t}=-22.337470-0.145865 \ln K_{t}+1.748346 \ln L_{t}+-0.013067 \ln E_{t} \\
&+0.007516\left(\ln K_{t}\right)^{2}+0.076086\left(\ln L_{t}\right)^{2}+0.001052\left(\ln E_{t}\right)^{2} \\
&+0.012340\left(\ln K_{t} \ln L_{t}\right)+0.007475\left(\ln K_{t} \ln E_{t}\right) \\
&+ 0.000447\left(\ln L_{t} \ln E_{t}\right)
\end{aligned}
$$


Figure 2. Actual GDP and Estimated GDP according to Ridge Regression.

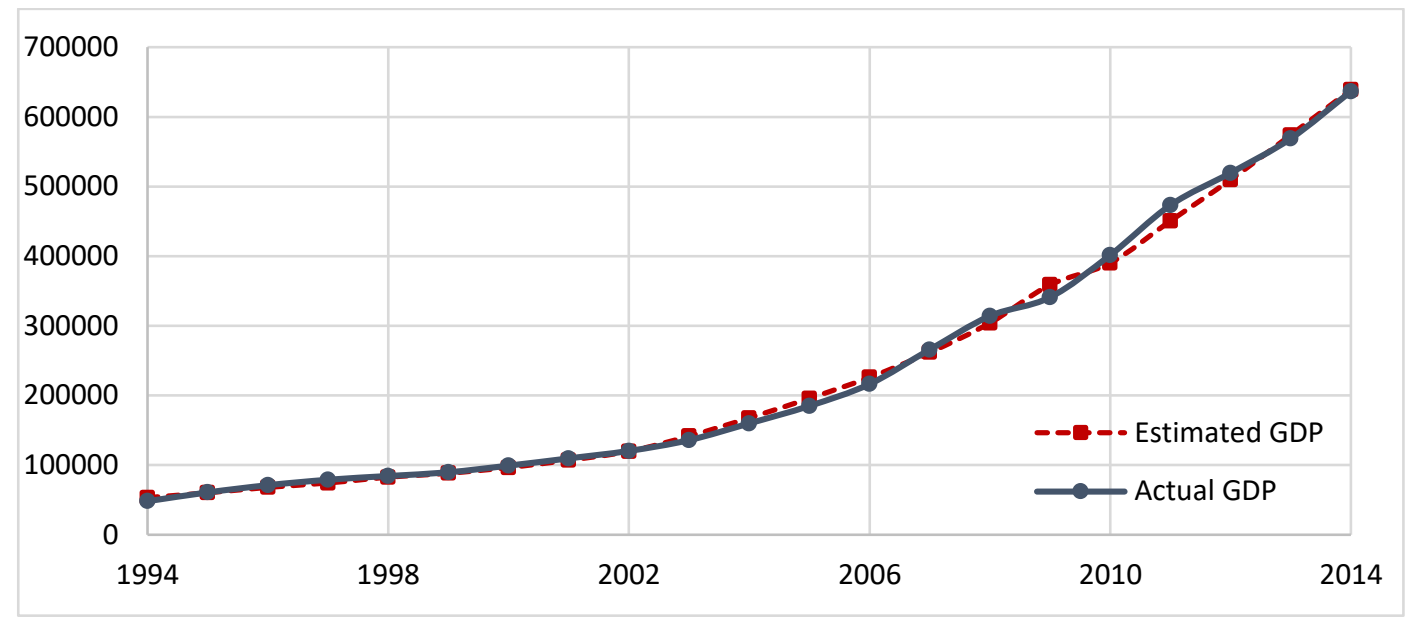

The actual and the estimated GDP values obtained by using Ridge regression equation is shown in Fig.2. The output elasticities for each input are calculated and shown in Table 5.

Table 5. Output elasticities for each input

\begin{tabular}{cccc}
\hline Year & $\boldsymbol{f}_{\boldsymbol{K}}$ & $\boldsymbol{f}_{\boldsymbol{L}}$ & $\boldsymbol{f}_{\boldsymbol{E}}$ \\
\hline 1994 & 0.51713 & 1.89821 & 0.08939 \\
1995 & 0.52015 & 1.90034 & 0.09074 \\
1996 & 0.52277 & 1.90213 & 0.09187 \\
1997 & 0.52414 & 1.90317 & 0.09250 \\
1998 & 0.52593 & 1.90469 & 0.09339 \\
1999 & 0.52690 & 1.90534 & 0.09379 \\
2000 & 0.52875 & 1.90662 & 0.09460 \\
2001 & 0.53096 & 1.90820 & 0.09559 \\
2002 & 0.53382 & 1.91026 & 0.09688 \\
2003 & 0.53864 & 1.91358 & 0.09901 \\
2004 & 0.54342 & 1.91683 & 0.10111 \\
2005 & 0.54770 & 1.91989 & 0.10304 \\
2006 & 0.55167 & 1.92273 & 0.10484 \\
2007 & 0.55562 & 1.92563 & 0.10666 \\
2008 & 0.55981 & 1.92867 & 0.10858 \\
2009 & 0.56418 & 1.93201 & 0.11064 \\
2010 & 0.56637 & 1.93354 & 0.11162 \\
2011 & 0.57013 & 1.93631 & 0.11336 \\
2012 & 0.57325 & 1.93868 & 0.11482 \\
2013 & 0.57622 & 1.94093 & 0.11622 \\
2014 & 0.57927 & 1.94289 & 0.11751 \\
\hline Average & 0.54556 & 1.91860 & 0.10220 \\
\hline & & & \\
\hline
\end{tabular}

The output elasticities of variables of capital, labor and energy are given by years. We see that the output elasticity change with the time period $t$. These values 
represent that the output variables value fluctuation according to the sensitivity of input variables. Elasticities of substitution for the various inputs are calculated and shown and given in Table 6.

The elasticity of substitution between the pairs of capital, labor and energy is positive. It means that these variables can be substitute. Technological development increases economic growth. Technological progress is described by the output mines the contribution of capital, labor and energy. We can calculate the contribution rate of technological progress to output growth as,

$$
\alpha_{A}(t)=1-\alpha_{K}(t)-\alpha_{L}(t)-\alpha_{E}(t)
$$

where,

$$
\alpha_{K}(t)=f_{K}(t) \frac{\dot{K_{t}}}{K_{t}} / \frac{\dot{Q_{t}}}{Q_{t}}, \quad \alpha_{L}(t)=f_{L}(t) \frac{\dot{L_{t}}}{L_{t}} / \frac{\dot{Q_{t}}}{Q_{t}}, \quad \alpha_{E}(t)=f_{E}(t) \frac{\dot{E_{t}}}{E_{t}} / \frac{\dot{Q_{t}}}{Q_{t}}
$$

In the investigated time period, the contribution rate of technological progress to total GDP growth is on average $3.52 \%$.

Table 6. Substitution elasticity of input

\begin{tabular}{|c|c|c|c|}
\hline Year & $\sigma_{K L}$ & $\sigma_{K E}$ & $\sigma_{L E}$ \\
\hline 1994 & 0.99396 & 0.99677 & 1.01225 \\
\hline 1995 & 0.99389 & 0.99665 & 1.16627 \\
\hline 1996 & 0.99382 & 0.99656 & 1.09318 \\
\hline 1997 & 0.99379 & 0.99651 & 1.00486 \\
\hline 1998 & 0.99375 & 0.99643 & 0.99975 \\
\hline 1999 & 0.99373 & 0.99640 & 0.99975 \\
\hline 2000 & 0.99368 & 0.99634 & 0.99975 \\
\hline 2001 & 0.99363 & 0.99627 & 0.99975 \\
\hline 2002 & 0.99356 & 0.99618 & 0.99975 \\
\hline 2003 & 0.99344 & 0.99603 & 0.99975 \\
\hline 2004 & 0.99332 & 0.99590 & 0.99975 \\
\hline 2005 & 0.99322 & 0.99578 & 0.99975 \\
\hline 2006 & 0.99313 & 0.99568 & 0.99975 \\
\hline 2007 & 0.99303 & 0.99558 & 0.99975 \\
\hline 2008 & 0.99293 & 0.99548 & 0.99975 \\
\hline 2009 & 0.99283 & 0.99537 & 0.99975 \\
\hline 2010 & 0.99278 & 0.99532 & 0.99975 \\
\hline 2011 & 0.99269 & 0.99524 & 0.99975 \\
\hline 2012 & 0.99262 & 0.99518 & 0.99975 \\
\hline 2013 & 0.99255 & 0.99511 & 0.99975 \\
\hline 2014 & 0.99247 & 0.99507 & 0.99976 \\
\hline Average & 0.99328 & 0.99590 & 1.01297 \\
\hline
\end{tabular}
factors 
Figure 3. Estimated Capital according to Holt Winter's Method

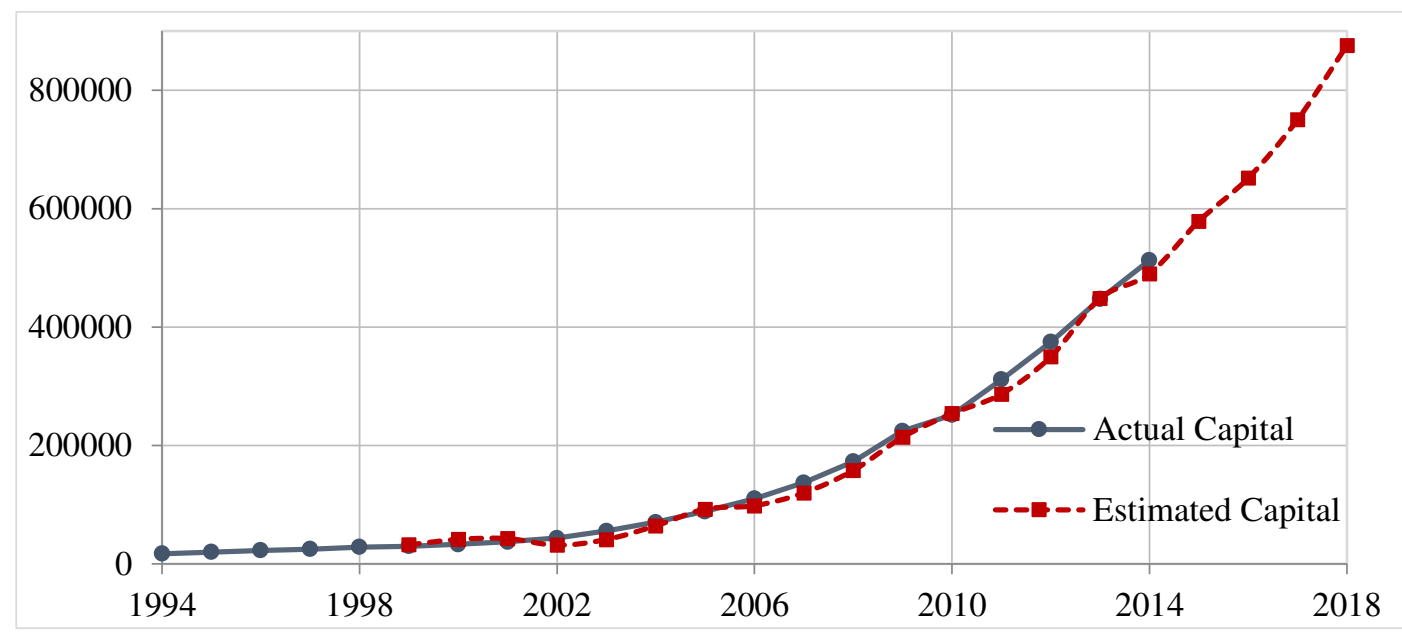

Figure 4. Estimated Labor according to Holt Winter's Method

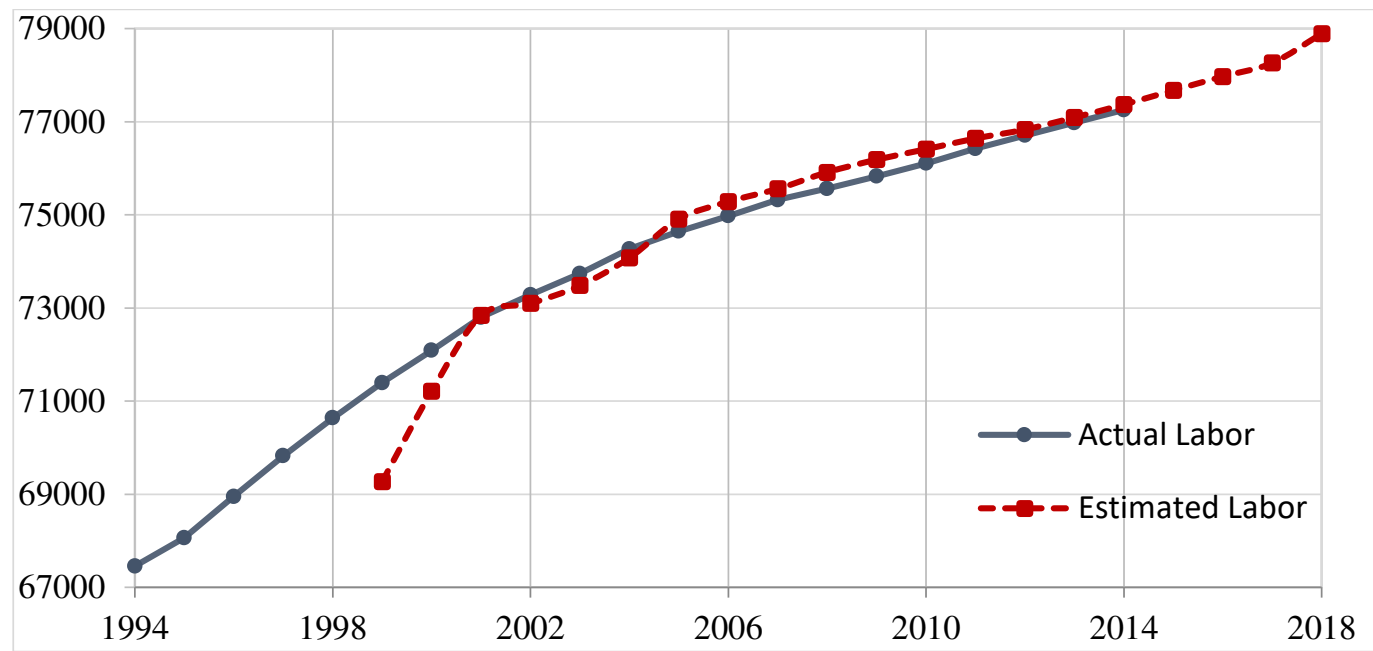

Figure 5. Estimated Energy according to Holt Winter's Method

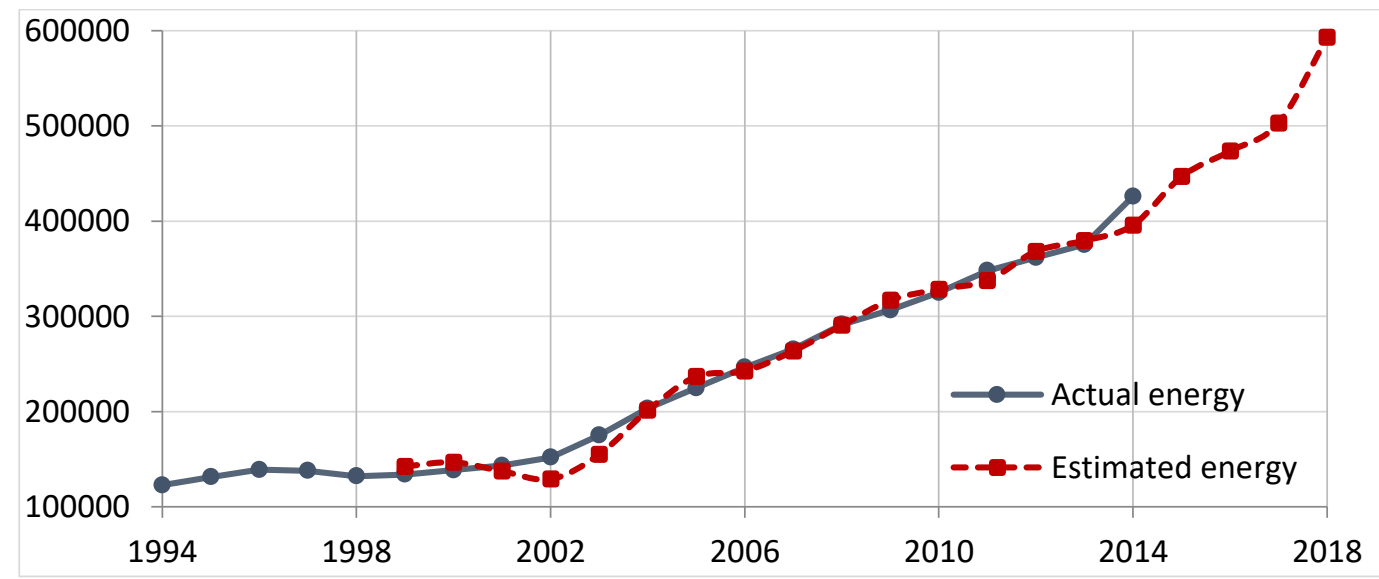


Figure 6. Estimated GDP according to Holt Winter's Method

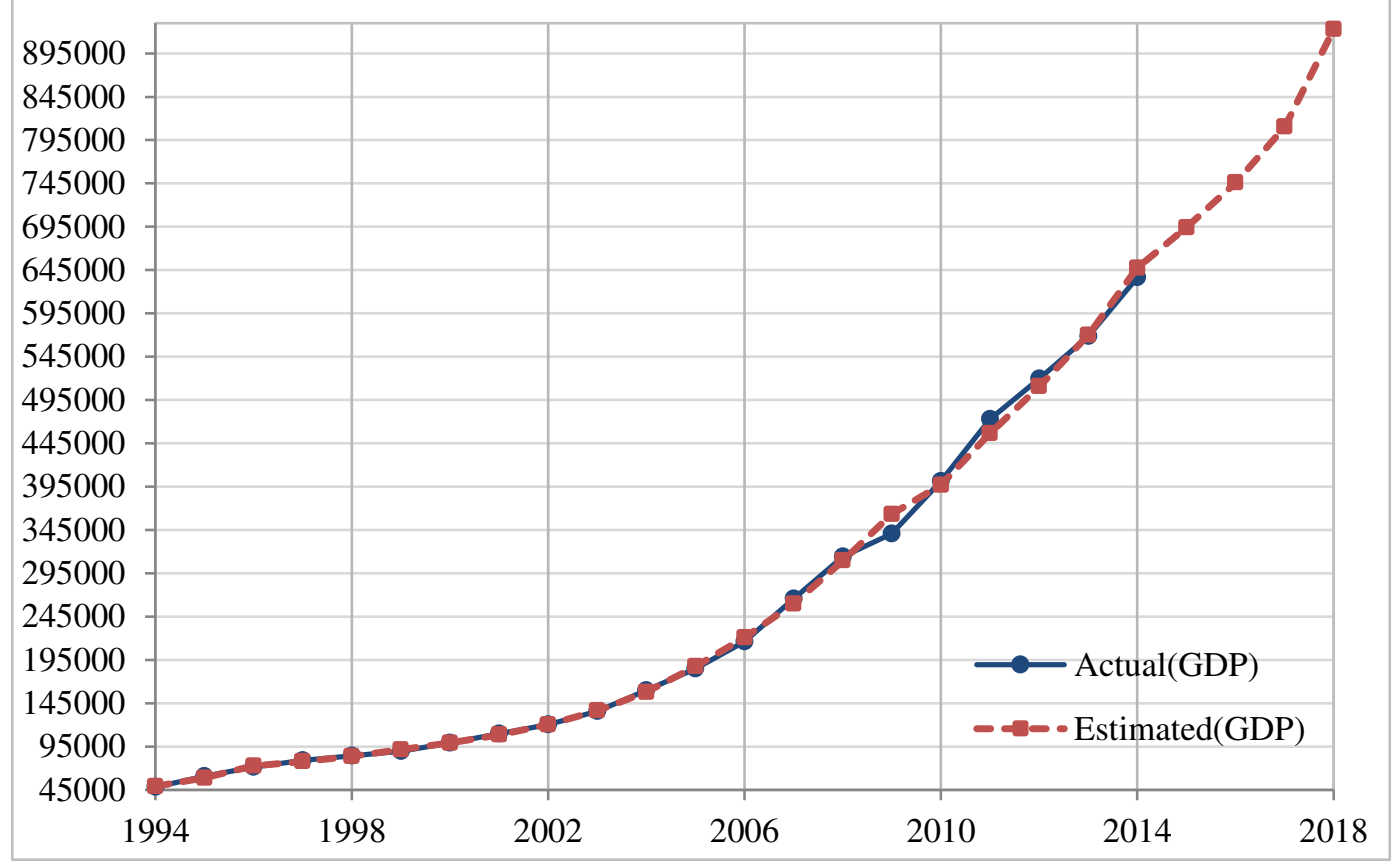

The study showed that the triple exponential smoothing method can be an appropriate approach for level estimation of capital, labor and energy inputs. The estimated values of GDP using Translog production function with capital, labor and energy inputs and estimated GDP values by IMF are given in Table 7.

Table 7. Comparison with the estimated GDP by IMF and estimated GDP

\begin{tabular}{llll}
\hline Year & $\begin{array}{l}\text { Estimated GDP } \\
\text { (billion yuan) }\end{array}$ & $\begin{array}{l}\text { Estimated GDP by IMF } \\
\text { (billion yuan) }\end{array}$ & $\begin{array}{l}\text { Actual GDP } \\
\text { (billion yuan) }\end{array}$ \\
\hline 2012 & 510619.59 & 534123 & 519470.1 \\
2013 & 570123.45 & 588018.8 & 568845 \\
2014 & 570123.45 & 636139 & 636462.7 \\
2015 & 694147.84 & 692391 & \\
2016 & 745874.42 & 742082.3 & \\
2017 & 810181.87 & 795409.2 & \\
2018 & 922848.73 & 856923.6 & \\
\hline
\end{tabular}

\subsection{Error Analysis}

Error Analysis is needed for examining the precision of forecasted results. The Mean Absolute Percentage Error (MAPE) is one of the most widely used methods which is evaluation of forecasting error. The MAPE is calculated as, 


$$
M A P E=\frac{1}{n} \sum_{t=1}^{n} \frac{\left|Q_{t}-\hat{Q}_{t}\right|}{Q_{t}}
$$

Where $Q_{t}$ is the actual value. $\hat{Q}_{t}$ is also forecasting value at time t. $n$ is the number of periods forecasted. MAPE reference values for forecasting accuracy are shown in Table 8 (Lewis, 1982).

Table 8. MAPE reference values for forecasting accuracy

\begin{tabular}{ll}
\hline MAPE & Forecasting Accuracy \\
\hline Less than $10 \%$ & Highly accurate \\
$11 \%$ to $20 \%$ & Good forecast \\
$21 \%$ to $50 \%$ & Reasonable forecast \\
$51 \%$ or more & Inaccurate forecast \\
\hline
\end{tabular}

Table 9. MAPE values for Translog and CES production functions

\begin{tabular}{lll}
\hline & MAPE & Forecasting Accuracy \\
\hline Translog production function & $3.39 \%$ & Highly Accurate \\
CES production function & $3.31 \%$ & Highly accurate \\
\hline
\end{tabular}

\section{Conclusion}

In this paper, CES production function model and Translog production function model are implemented to estimate the future values of the GDP which is an indicator of China economic growth with capital, labor and energy input factors.

Firstly, we implemented the CES production model with capital and labor input factors to observed data. The findings of CES model reveals that the elasticity of substitution between capital - labor bundle is $\sigma=1.085$ and MAPE value is 0.03423. The CES model with capital and labor inputs gives a reliable forecast of GDP, the nested CES production model can give more reliable results for large data set. Because we have a small number of data, we did not use the nested CES model in the real application.

Secondly, we implemented the quadratic Translog production function with capital, labor and energy inputs to the dataset. In the empirical analysis, it is founded 
the evidence of multicollinearity between variables. To eliminate the multicollinearity, it is used to the Ridge regression method.

The Translog function is more convenient than CES function because it has a very flexible structure. The output elasticities of input factors which are changing by time are calculated by using the fitted model. Empirical findings show that Ridge regression parameters are consistent with actual economic situation and Translog production function is a good explanatory model for China GDP values.

The output elasticity of each input factor and the elasticity of substitution between these input factors are analyzed. The output elasticities of capital, labor and energy are indicated that all of the input factors have a significant positive impact on China economy in the studied period. The output elasticity of labor is slightly larger than the capital and energy elasticities. This also shows that labor input has a leading role in promoting economic growth. The fluctuation range of output elasticities of capital and labor is stable by years, however, the output elasticity of energy is gradually increasing by years.

The contribution rate of technological progress to total GDP growth is found on average $3.52 \%$ in the investigated time period.

Finally, in general, the total production of the China economy highly depends on labor and capital inputs, besides the effect of energy input is relatively small.

\section{Acknowledgements}

Any errors or omissions are the fault of the authors. Thank editor and anonymous referees for the useful comments.

\section{Authors' contributions}

Hülya Başeğmez and Ömer Önalan worked together in all stages of the article and shared the responsibilities equally in the analysis and writing stage. We take responsibility for our views. All authors have read and approved the final manuscript.

\section{Funding}

This research did not receive any specific grant from funding agencies in the public, commercial, or not-for-profit sectors. 


\section{Availability of data and materials}

The data sources of all data analyzed during this study are introduced in the first part of "Empirical Analysis" section.

\section{Competing interests}

I declare no potential competing interests.

\section{Authors' information}

Ömer ÖNALAN ${ }^{1}$

Faculty of Business Administration, Marmara University, Istanbul, Turkey, E-mail: omeronalan@marmara.edu.tr

Hülya BAŞEĞMEZ2

Faculty of Economics and Administrative Sciences, Beykent University, Istanbul, Turkey, E-mail: hulyabasegmez@gmail.com

\section{REFERENCES}

Arrow, K.J., Chenery, H.B., Minhas, B.S., Solow, R.M., 1961. Capital-Labor Substitution and Economic Efficiency. Rev. Econ. Stat. 43, 225-250.

Benhabib, J., Spiegel, M.M., 1994. The role of human capital in economic development evidence from aggregate cross-country data. J. Monet. Econ. 34, 143-173. https://doi.org/10.1016/0304-3932(94)90047-7

Cheng, M., Han, Y., 2017. Application of a New Superposition CES Production Function Model. J. Syst. Sci. Inf. 5, 462-472. https://doi.org/10.21078/JSSI-2017-462-11

Christensen, L.R., Jorgenson, D.W., Lau, L.J., 1973. Transcendental Logarithmic Production Frontiers. Rev. Econ. Stat. 55, 28-45.

Dhakre, D.S., Sarkar, K.A., Manna, S., 2016. Forecast Price of Brinjal By Holt Winters Method in West Bengal Using Ms Excel. Int. J. Bio-Envoironment Agric. Sci. 2, 232236.

Hamilton J. D., 1994. Time-Series Analysis. Princeton University Press, Princeton. https://doi.org/10.2307/1270781

Henningsen, A., Henningsen, G., 2012. On Estimation of The CES Production FunctionRevisited. Econ. Lett. 115, 67-69. https://doi.org/10.1016/j.econlet.2011.12.007

Henningsen, A., Henningsen, G., Van der Werf, E., 2019. Capital-Labour-Energy Substitution in A Nested CES Framework: A Replication and Update of Kemfert (1998). Energy Econ. Article in. https://doi.org/10.1016/j.eneco.2017.12.019

Hoerl, A.E., Kennard, R.W., 1970. Ridge Regression : Applications to Nonorthogonal Problems. Technometrics 12, 69-82. 
Hoff, A., 2002. The translog approximation of the constant elasticity of substitution production function with more than two input variables. Fødevareøkonomisk Institut.

Hossain, M.M., Majumder, A.K., Basak, T., 2013. An Application of Non-Linear CobbDouglas Production Function to Selected Manufacturing Industries in Bangladesh. Open J. Stat. 173-178. https://doi.org/10.4236/ojs.2012.24058

Hrishikesh D. Vinod, 1978. A Survey of Ridge Regression and Related Techniques for Improvements over Ordinary Least Squares. Rev. Econ. Stat. 60, 121-131.

Kemfert, C., 1998. Estimated substitution of a nested CES production function approach for Germany. Energy Econ. 20, 249-264.

Kmenta, J., 1967. On Estimation of the CES Production Function. Int. Econ. Rev. (Philadelphia). 8, 180-189.

Lewis, C.D., 1982. Industrial and business forecasting methods: A practical guide to exponential smoothing and curve fitting. London : Butterworth Scientific.

Lin, B., Ahmad, I., 2016. Energy substitution effect on transport sector of Pakistan based on trans-log production function. Renew. Sustain. Energy Rev. 56, 1182-1193. https://doi.org/10.1016/j.rser.2015.12.012

Lin, B., Liu, W., 2017. Estimation of energy substitution effect in China's machinery industry-based on the corrected formula for elasticity of substitution. Energy 129, 246-254. https://doi.org/10.1016/j.energy.2017.04.103

Lloyd, P.J., MacLaren, D., 2002. Measures of trade openness using CGE analysis. J. Policy Model. 24, 67-81. https://doi.org/10.1016/S0161-8938(01)00096-5

Lucas Jr., R.E., 1988. On the mechanics of economic development. J. Monet. Econ. 22, 3-4. https://doi.org/Doi 10.1016/0304-3932(88)90168-7

Mahaboob, B., Venkateswarlu, B., Balasiddamuni, P., 2017. Estimation of Parameters of Generalized Cobb-Douglas production Functional Model. IJPT 9, 29181-29188.

Mankiw, N.G., Romer, D. and Weil, D.., 1992. A contribution to the empirics of Economic Growth. Q. J. Econ. 407-437. https://doi.org/10.1016/j.jpolmod.2014.01.001

McFadden, D., 1963. Constant elasticity of substitution production functions. Rev. Econ. Stud. 30, 73-83.

McFarland, J.R., Reilly, J.M., Herzog, H.J., 2004. Representing energy technologies in top-down economic models using bottom-up information. Energy Econ. 26, 685707. https://doi.org/10.1016/j.eneco.2004.04.026

Muniz, G., Kibria, B.M.G., 2009. On some ridge regression estimators: An empirical comparisons. Commun. Stat. Simul. Comput. 38, 621-630.

https://doi.org/10.1080/03610910802592838

Onalan, O., Basegmez, H., 2018. Estimation of economic growth using Grey Cobb- 
Douglas production function: An application for US economy. J. Business, Econ. Financ. 7, 178-190. https://doi.org/10.17261/Pressacademia.2018.840

Papageorgiou, C., Saam, M., 2008. Two-level CES production technology in the solow and diamond growth models. Scand. J. Econ. 110, 119-143. https://doi.org/10.1111/j.1467-9442.2008.00529.x

Prado, R., West, M., 2010. Time series: Modelling, Computation and Inference. CRC Press.

Raymond W. Goldsmith, 1951. A Perpetual Inventory of National Wealth. In Studies in Income and Wealth. https://doi.org/DOI 10.1002/chem.200903127

Romer, P.M., 1986. Increasing Returns and Long-Run Growth. J. Polit. Econ. 94, 10021037. https://doi.org/10.1086/261420

Stern, D.I., 2011. Elasticities of substitution and complementarity. J. Product. Anal. 36, 79-89. https://doi.org/10.1007/s11123-010-0203-1

Thursby, J.G., Lovell, C.A.K., 1978. An Investigation of the Kmenta Approximation to the CES Function. Int. Econ. Rev. (Philadelphia). 19, 363-377.

Uzawa, H., 1962. Production Functions with Constant Elasticities of Substitution. Rev. Econ. Stud. 29, 291. https://doi.org/10.2307/2296305 
Figures

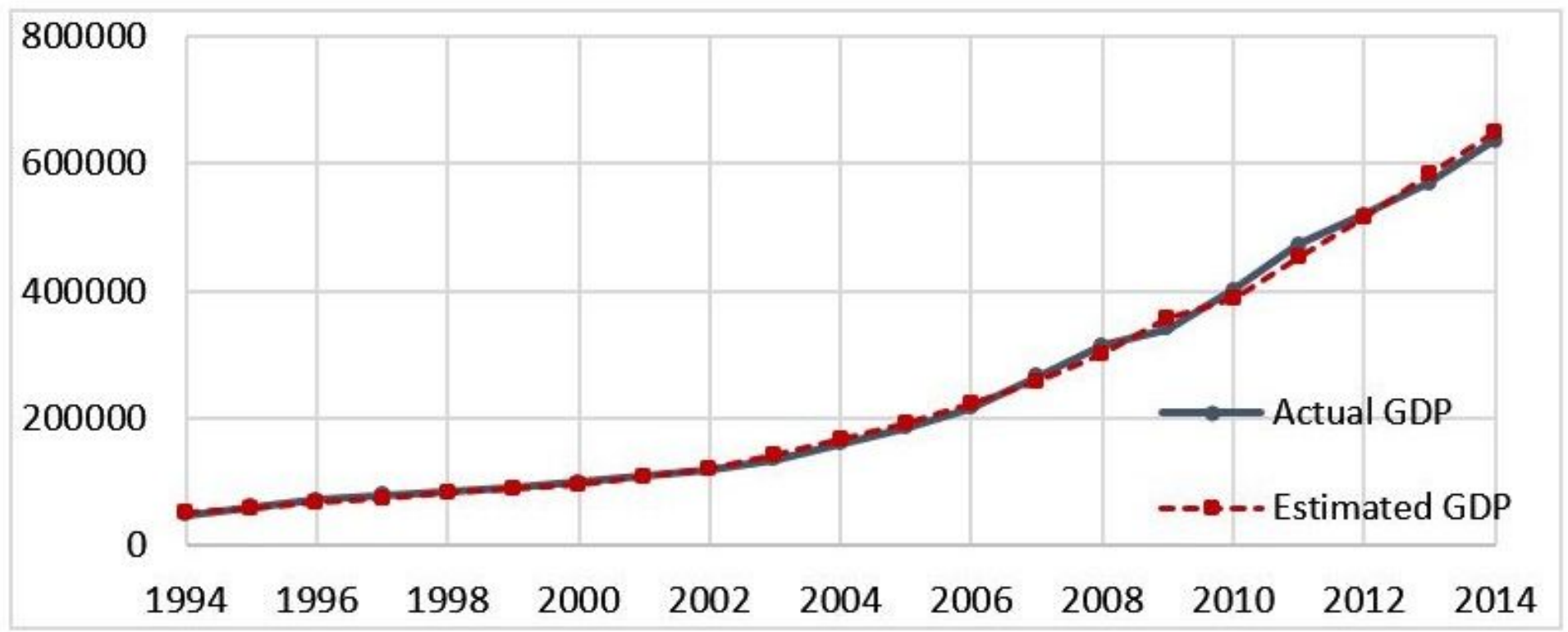

Figure 1

Actual GDP and Estimated GDP obtained from Kmenta Approach

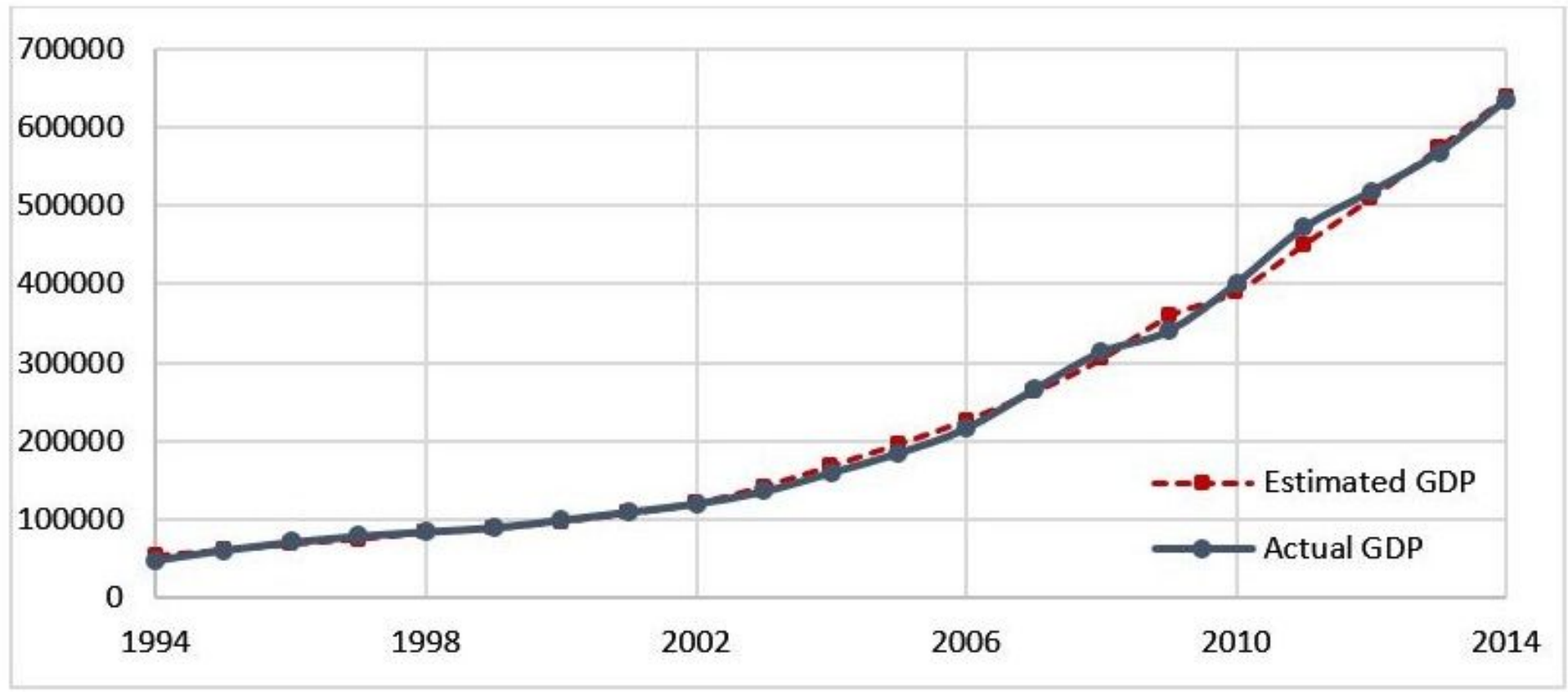

Figure 2

Actual GDP and Estimated GDP according to Ridge Regression. 


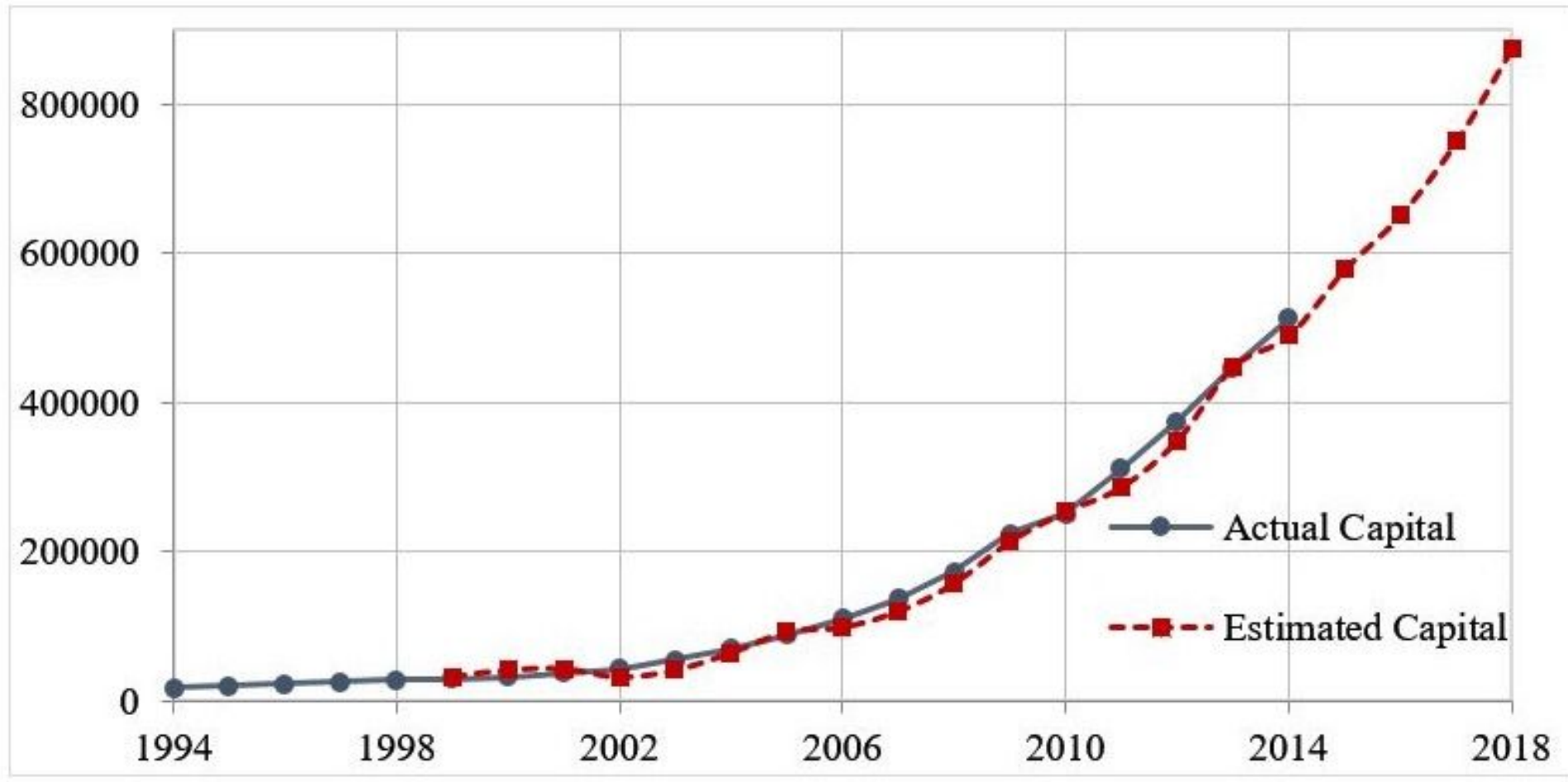

Figure 3

Estimated Capital according to Holt Winter's Method

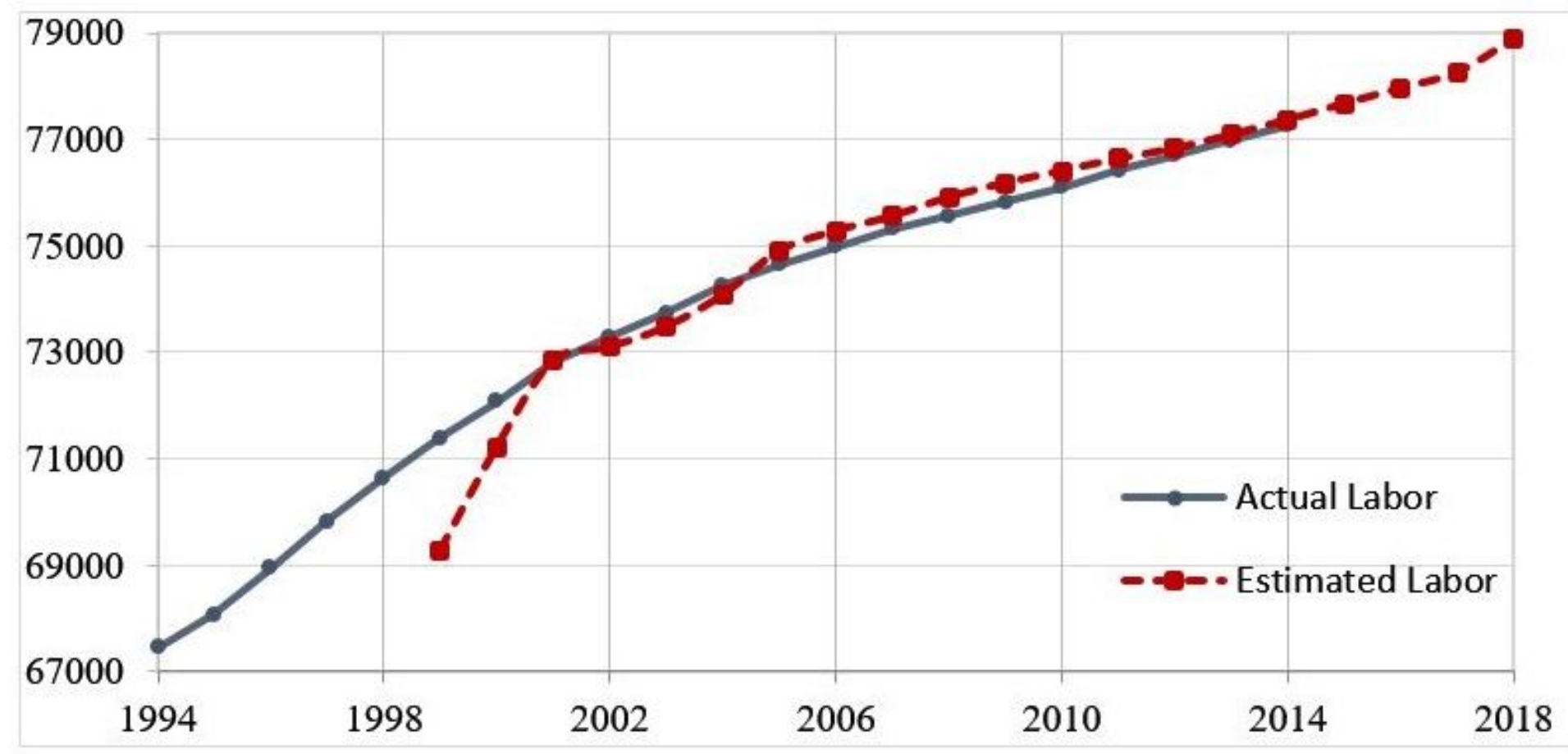

Figure 4

Estimated Labor according to Holt Winter's Method 


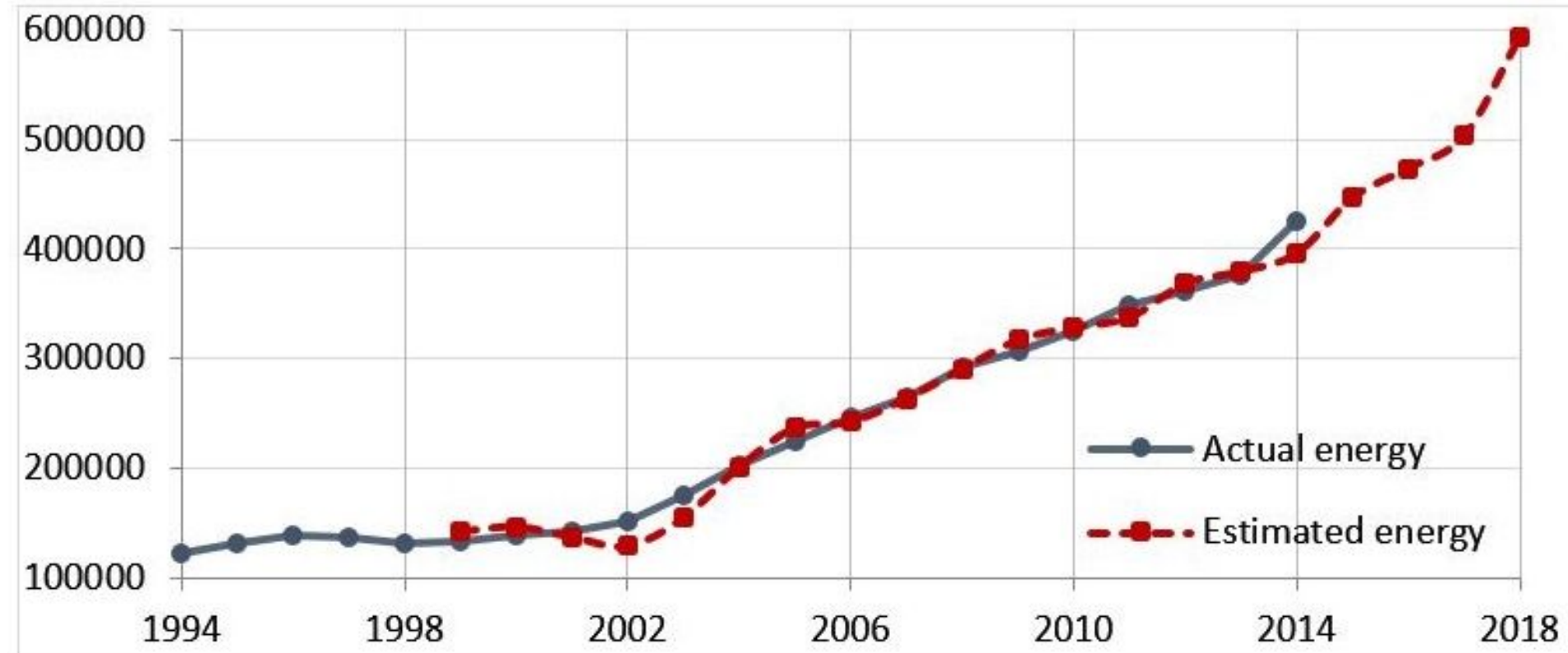

Figure 5

Estimated Energy according to Holt Winter's Method

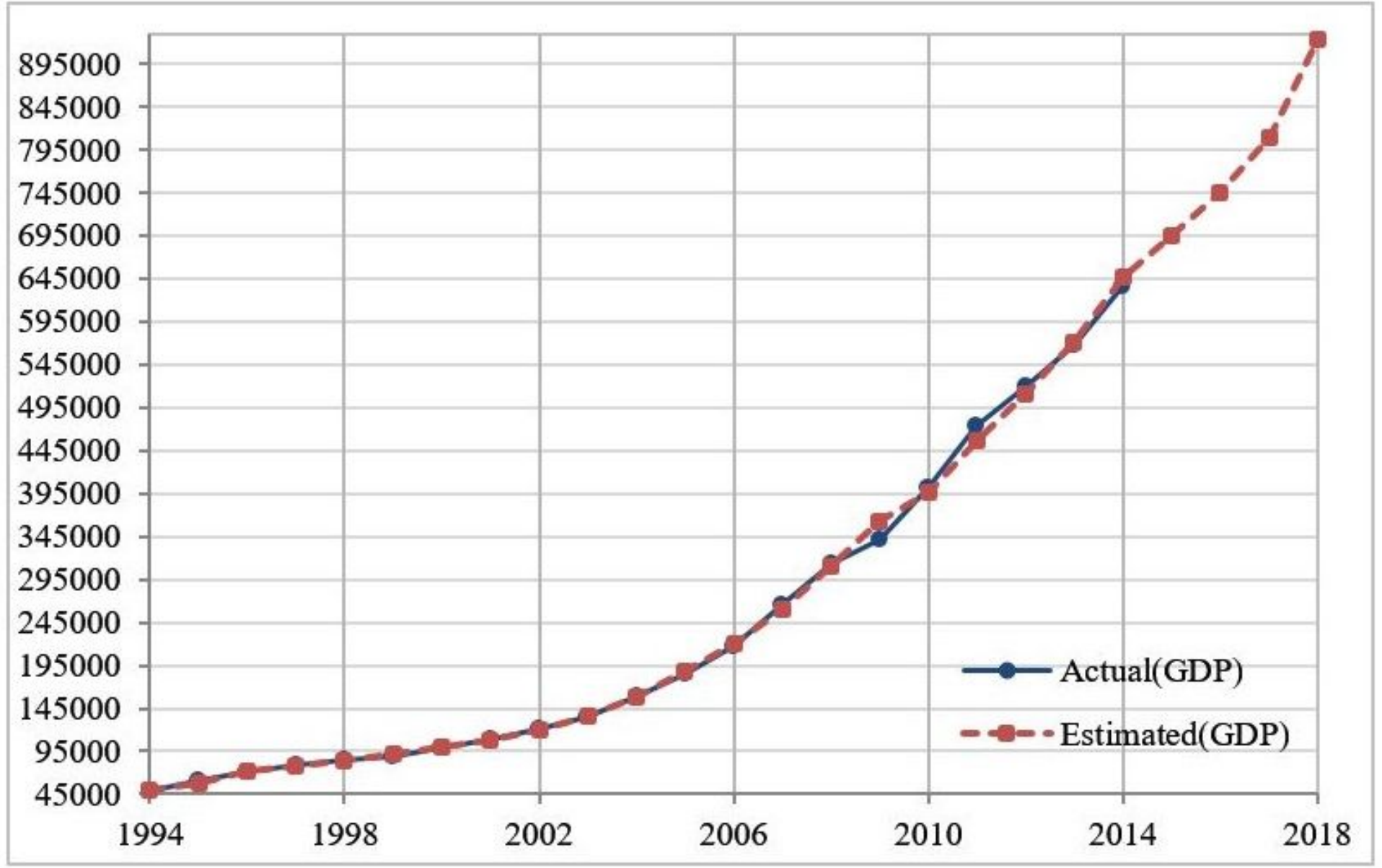

Figure 6

Estimated GDP according to Holt Winter's Method 


\section{Supplementary Files}

This is a list of supplementary files associated with this preprint. Click to download.

- data.xlsx 